\title{
Asymmetric cross- and self-aldol reactions of aldehydes in water with a polystyrene- supported triazolylproline organocatalyst
}

\author{
Patricia Llanes, ${ }^{a}$ Sonia Sayalero, ${ }^{a}$ Carles Rodríguez-Escrich ${ }^{a}$ and Miquel A. Pericàs*a,b \\ a. Institute of Chemical Research of Catalonia (ICIQ), The Barcelona Institute of Science and Technology. Av. Països Catalans, 16, 43007 Tarragona, Spain. E-mail: \\ mapericas@iciq.es.

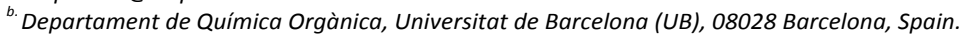

A polystyrene-immobilized triazolylproline has been prepared by a bottom-up approach involving co-polymerization with full regiocontrol. The resulting PS resin swells in water and has been applied to the enantioselective cross-aldol reaction and to the self-aldol reaction of aldehydes under essentially neat conditions, excellent yields and stereoselectivities being recorded.

\section{Introduction}

The aldol reaction is the most important method to install the $\beta$-hydroxycarbonyl structural unit, very common in fine chemicals and pharmaceutically active compounds. ${ }^{1}$ The myriad studies devoted to the topic deal almost exclusively with ketone donors and aromatic aldehyde acceptors. In contrast, the direct asymmetric cross-aldol coupling between non-equivalent aldehydes, first reported by MacMillan and co-workers, ${ }^{2}$ remains a synthetic challenge. Since enolizable aldehydes can play a double role as nucleophiles or electrophiles, controlling reaction pathways is crucial to achieve the desired chemoselectivity. ${ }^{3}$

The use of proline to carry out this transformation in a stereoselective manner presents several advantages: it is safe, inexpensive and stable to moisture and air, which allows this metal-free process to take place in very benign reaction conditions. ${ }^{4}$ Proline-catalyzed asymmetric aldol reactions are usually carried out in polar solvents such as DMSO or DMF. However, since the use of binary mixtures of polar aprotic solvents and water has a highly beneficial effect in the reaction rate, ${ }^{5}$ the possibility of using water as reaction medium is very appealing to reduce the environmental impact of the process. ${ }^{6}$ In addition, the undesired formation of $\alpha, \beta$-unsaturated aldehydes arising from dehydration of the initial aldol adduct, is minimized under aqueous conditions. ${ }^{7}$

Given the interest in the asymmetric aldol reaction, several authors have described the immobilization of proline derivatives with the common goal of increasing their sustainability profile. ${ }^{8}$ Solid-supported catalysts are easily separated from the reaction mixture, thereby facilitating product isolation and opening up the possibility of recovery and reuse. Indeed, excellent results have been achieved using insoluble supports such as mesoporous silica ${ }^{9}$ and different classes of nanostructured ${ }^{10}$ or polymeric materials. ${ }^{11,12}$

Lightly cross-linked PS (1-2\% DVB) has good swelling characteristics in a variety of organic solvents, which generates a gel-type material. However, the limited compatibility of water with polystyrene (PS) resins usually hampers the use of PS-supported catalysts in an aqueous environment, albeit this issue can be circumvented. For instance, we have previously demonstrated that, with the appropriate design, PS-supported organocatalysts can generate a hydrophilic pocket, akin to that of aldolases, that allows working in water with high efficiency. ${ }^{11 \mathrm{a}-\mathrm{c}}$ To this end, it would be desirable to develop more efficient synthetic methods to prepare these catalytic resins without having to resort to pre-functionalized commercially available materials. This approach would significantly lower the cost of the catalytic material, an important parameter when large scale applications are conceived, and introduce the possibility of preparing custom-made resins with fully controllable parameters like loading, cross-linking level, and site-selective functionalization. ${ }^{12 \mathrm{~g}, \mathrm{~h}}$ In this last respect, it has been normally overlooked that commercial Merrifield resins, the most usual starting materials, contain in their structures variable mixtures of para- and meta-chloromethyl substituted phenyl rings, this fact being a potential origin of reproducibility issues in their preparation and catalytic applications.

\section{Results and discussion}

Herein we wanted to evaluate the possibility of a bottom-up approach towards catalytic resins, where a $p$-vinyl substituted monomeric species would be co-polymerized with styrene and divinylbenzene (DVB) in order to achieve strictly $p$-phenyl functionalized copolymers. Bearing in mind our ultimate goal of efficient operation in water, we decided to introduce a light cross-linking level ( $2 \% \mathrm{DVB})$, with the aim of generating a microporous resin that could swell in that media. ${ }^{11 a-c}$ 


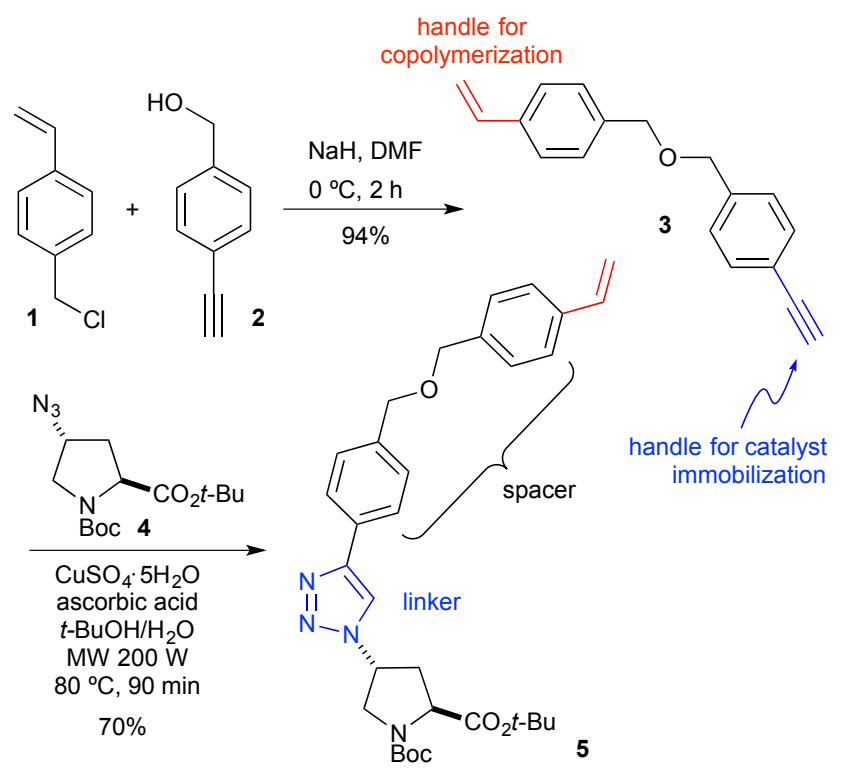

Scheme 1 Synthesis of the functional monomer 5

To this end, a proline derivative bearing a pendant vinyl group was prepared as indicated in Scheme 1 . First, $p$ chloromethylstyrene (1) was reacted with alcohol $\mathbf{2}$ to give the bifunctional linker $\mathbf{3}$. The terminal alkyne was clicked with the azidoproline derivative $4{ }^{11 \mathrm{~b}}$ yielding $\mathbf{5}$ in $70 \%$ yield. This monomer features the desired catalytic unit bound to a polymerizable vinyl group through a robust triazole unit, ${ }^{13}$ whose function is providing optimal hydrophobic/hydrophilic balance in the resin. According to precedents, ${ }^{11 \mathrm{~b}-\mathrm{d}}$ this situation gives rise to a hydrogen bond network that connects the linker with the amino acid, which explains why the resin, in spite of its highly lipophilic backbone, swells perfectly in water. On the other hand, a suitable spacer ensures enough distance between the catalytic site and the polymeric matrix, thus avoiding undesirable interactions which might affect the catalytic activity and/or selectivity.

The heterogeneous catalyst with the desired morphology and properties was obtained by AlBN-initiated radical copolymerization of the proline derivative $\mathbf{5}$ with styrene and DVB under the usual conditions for a suspension-type polymerization (Scheme 2) ${ }^{14,15}$ Trifluoroacetic acid-mediated deprotection of both the Boc group and the tert-butyl ester in 6 furnished the catalytically active resin 7 (Scheme 2), which was finally treated with a buffer solution ( $\mathrm{pH} 5$ ) to ensure proline is in its zwitterionic form. 

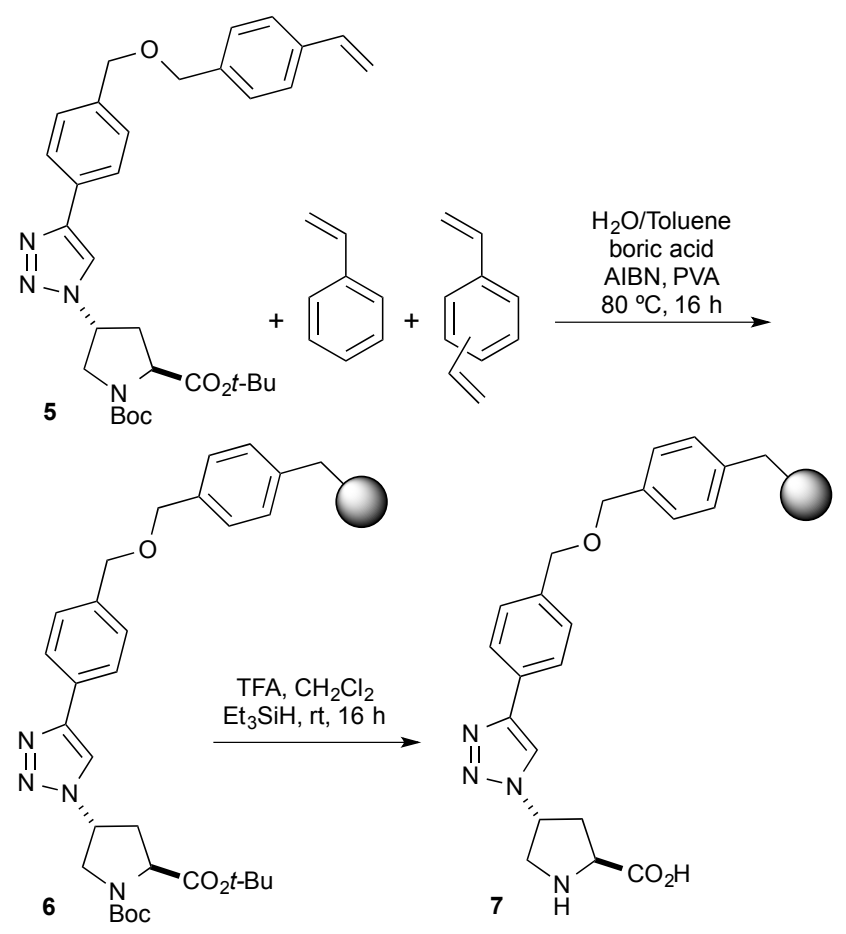

Scheme 2 Synthesis of the regioisomerically defined polystyrene-supported catalyst 7

An $86 \%$ of the monomer was incorporated to resin 7 , giving a functionalization level of $0.9 \mathrm{mmol} \mathrm{g}^{-1}$. Solvent uptake data of resin 7 were recorded for water, and aqueous mixtures of THF, DMF or DMSO (see Supporting Information). Notably, this new polymer proved to swell in water thanks to the cooperative effect between the triazole and the amino acid unit. ${ }^{11 b, c}$ This reveals the amphiphilic nature of the polymer: on the one hand it displays a hydrophobic matrix and, on the other hand, hydrophilic reactive centres are regularly scattered within its structure.

The asymmetric cross-aldol reaction between butanal and 2-nitrobenzaldehyde was chosen as a model to optimize the reaction conditions. As highlighted in Table 1, the reaction takes place at room temperature with 10 mol\% of 7 in different aqueous solvent systems. To our delight, using water as the only solvent (entry 1 ) the cross-aldol product was obtained in $80 \%$ yield and excellent stereoselectivity (93:7 anti/syn, $95 \%$ ee). A similar result was obtained with DMSO containing $6 \%$ of water (entry 2 ) or in a DMSO/water 1:1 mixture (entry 3). With wet DMF and THF the stereoselectivities were also very good, albeit the yield was lower in the latter case (entries 4-7). Using butanal in excess ensured excellent yields of the desired product while its homodimerization was practically negligible. For the sake of comparison, an analogous PS-supported triazolylproline previously reported by our group ${ }^{11 c}$, derived from commercial Merrifield resin (mixture of meta and para regioisomers) was tested in the benchmark reaction, giving the desired product in $85 \%$ yield, but only $84 \%$ ee.

Table 1 Solvent effects on the cross-aldol reaction of 2-nitrobenzaldehyde with butanal catalyzed by resin $\mathbf{7}^{\mathrm{a}}$

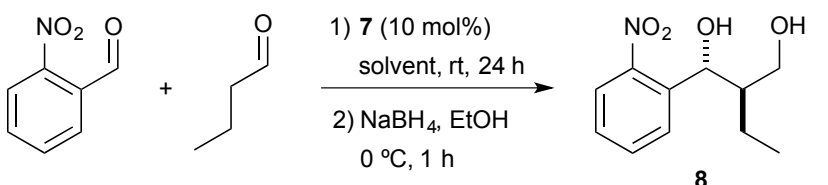

\begin{tabular}{ccccc}
\hline Entry & Solvent & $\begin{array}{c}\text { Yield } \\
{[\%]^{\mathrm{b}}}\end{array}$ & anti/syn & $\begin{array}{c}\text { ee } a n t i \\
{[\%]^{\mathrm{d}}}\end{array}$ \\
\hline 1 & $\mathrm{H}_{2} \mathrm{O}$ & 80 & $93: 7$ & 95 \\
2 & $\mathrm{DMSO} / \mathrm{H}_{2} \mathrm{O}(94: 6)$ & 80 & $93: 7$ & 96 \\
3 & $\mathrm{DMSO} / \mathrm{H}_{2} \mathrm{O}(50: 50)$ & 79 & $93: 7$ & 93 \\
4 & $\mathrm{DMF} / \mathrm{H}_{2} \mathrm{O}(94: 6)$ & 80 & $92: 8$ & 95 \\
5 & $\mathrm{DMF} / \mathrm{H}_{2} \mathrm{O}(50: 50)$ & 81 & $93: 7$ & 87 \\
6 & $\mathrm{THF} / \mathrm{H}_{2} \mathrm{O}(94: 6)$ & 56 & $93: 7$ & 96 \\
7 & $\mathrm{THF} / \mathrm{H}_{2} \mathrm{O}(50: 50)$ & 72 & $92: 8$ & 91
\end{tabular}

${ }^{a}$ Reactions were performed with resin $7(0.02 \mathrm{mmol}), 2$-nitrobenzaldehyde $(0.2 \mathrm{mmol})$ and butanal $(0.6 \mathrm{mmol})$ in different solvents $(67 \mu \mathrm{L}) .{ }^{\mathrm{b}}$ Isolated yield. ${ }^{\mathrm{c}}$ Determined by ${ }^{1} \mathrm{H}$ NMR on a crude sample of the 1,3 -diol. ${ }^{d}$ Determined by chiral HPLC . 
A representative family of aromatic aldehydes was then reacted with donor aliphatic aldehydes under the two best sets of conditions (A: water; B: wet DMSO; Table 2). Electron-deficient aromatic aldehydes such as $o$-nitro-, $p$-nitro-, $p$-cyano-, $p$ trifluoromethyl- and $o$-chlorobenzaldehyde reacted with butanal or propanal in very good yields and ee's, regardless of the substitution pattern (products 8-12, conditions A). The use of wet DMSO (containing 6\% of water) as solvent gave the corresponding adducts with similar results (conditions B). Remarkably, the concentration of the limiting aldehyde was $3 \mathrm{M}$ in both solvent systems.

When benzaldehyde was employed as the reaction partner the use of water gave much higher yield than wet DMSO, albeit the stereoselectivities were almost identical (product 13). 3-Methoxybenzaldehyde and furfural (which required $48 \mathrm{~h}$ reaction time) were also suitable substrates, providing the aldol product in good to excellent yields and stereoselectivities (products 14-16). Again water gave much higher yields than wet DMSO (conditions A vs B), which seems to be a trend for electron rich aromatic aldehydes. In the latter case, neat conditions proved to be also suitable to carry out the reaction.

It is important to note that all the scope in Table 2 was carried out with two samples of $\mathbf{7}$ that were repeatedly reused. This illustrates the robustness of the resin, which displays excellent results with a wide variety of substrates.

Table 2 Asymmetric direct cross-aldol reaction of non-equivalent aldehydes catalyzed by resin $7^{\mathrm{a}}$

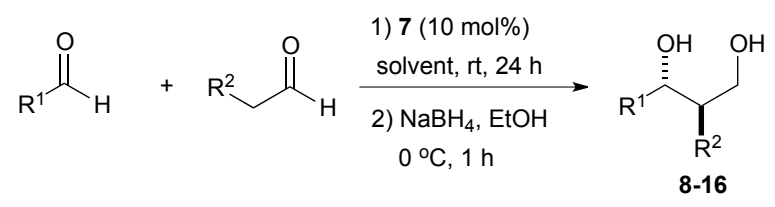<smiles>CCC(CO)[C@H](O)c1ccccc1[N+](=O)[O-]</smiles><smiles>CCC(CO)[C@H](O)c1ccc([N+](=O)[O-])cc1</smiles><smiles>CCC(CO)[C@H](O)c1ccc(C#N)cc1</smiles>
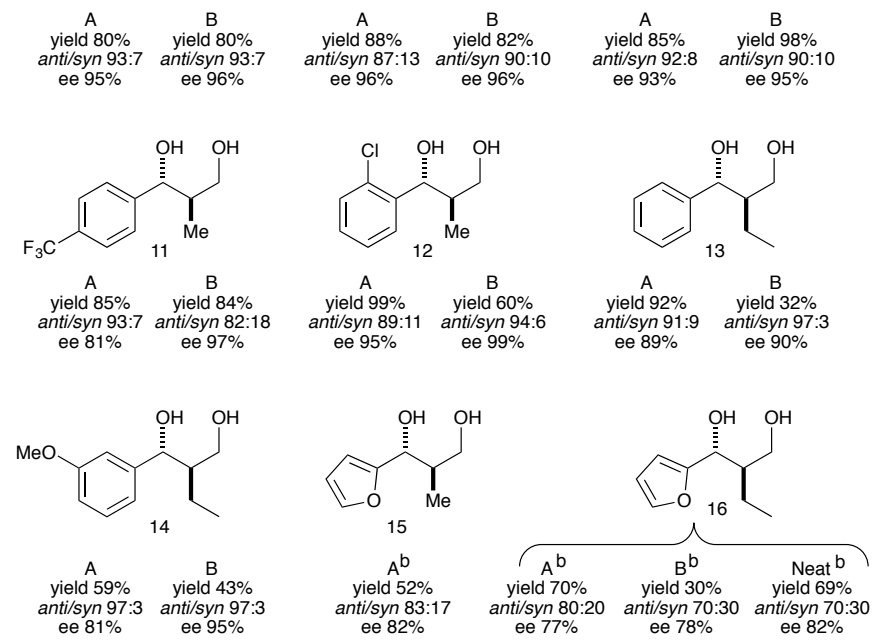

${ }^{\text {a }}$ Typical reaction conditions: resin $7(0.02 \mathrm{mmol})$, aromatic aldehyde $(0.2 \mathrm{mmol})$ and aliphatic aldehyde $(0.6 \mathrm{mmol})$ in water $(67 \mu \mathrm{L}, \mathrm{Conditions} \mathrm{A})$ or in a mixture of DMSO/water (94:6, $67 \mu \mathrm{L}$, Conditions B); isolated yield; anti/syn diastereomeric ratio was determined by ${ }^{1} \mathrm{H}$ NMR on a crude sample of the 1,3 -diol; ee was determined by chiral HPLC. ${ }^{\text {b }} 48 \mathrm{~h}$ reaction time.

Having established that resin 7 effectively promoted the cross-aldol reaction of aldehydes in the presence of small amounts of aqueous solvents at room temperature, these conditions were applied to the self-aldol reaction of aldehydes using water as the only solvent. Initial investigations revealed that in the presence of $\mathbf{7}$ the self-aldol reaction of propanal works satisfactorily in water (Table 3). In these conditions, the self-aldol product undergoes hemiacetal formation with the starting aldehyde, which protects the product from epimerization or participation in further aldol processes. However, this consumes up to one third of the starting material and thus the yields in Table 3 refer to this hemiacetal product. To our convenience, diol $\mathbf{1 7}$ could be obtained in good yield and with good stereoselectivity after in situ reduction. As shown in Table 3, the reactions gave moderate to good yields but high enantioselectivities with propanal, butanal and 3-phenylpropanal. 


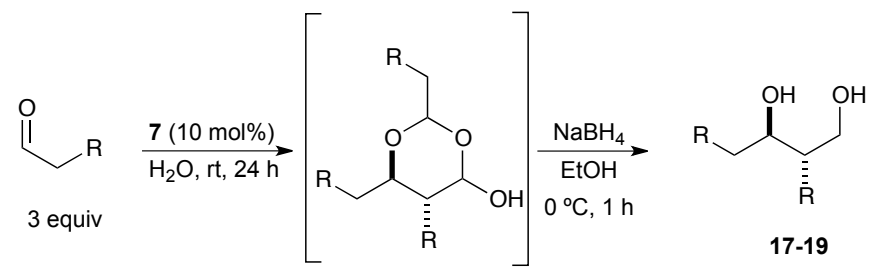

\begin{tabular}{cccccc}
\hline Entry & R & Product & Yield [\%] $^{\mathrm{b}}$ & anti:syn $^{\mathrm{c}}$ & ee anti $[\%]^{\mathrm{d}}$ \\
\hline 1 & $\mathrm{Me}$ & $\mathbf{1 7}$ & 30 & $70: 30$ & 91 \\
2 & Et & $\mathbf{1 8}$ & 82 & $60: 40$ & 87 \\
3 & $\mathrm{Bn}$ & $\mathbf{1 9}$ & 61 & $79: 21$ & $96^{\mathrm{e}}$ \\
$4^{\mathrm{f}}$ & $\mathrm{Bn}$ & $\mathbf{1 9}$ & 70 & $56: 44$ & 73 \\
\hline
\end{tabular}

${ }^{a}$ Reactions were performed in water $(0.4 \mathrm{~mL})$ with aldehyde $(1 \mathrm{mmol})$ and resin $7(0.1 \mathrm{mmol}) .{ }^{\mathrm{b}}$ Isolated yield. ${ }^{\mathrm{c}}$ Determined by ${ }^{1} \mathrm{H} \mathrm{NMR}$ on a crude sample of the $1,3-$ diol (entries 1, 2) or non chiral HPLC (entries 3, 4). ${ }^{d}$ Determined by chiral HPLC after conversion to the monobenzoate. ${ }^{e}$ Determined by chiral HPLC of the $1,3-$ diol. ${ }^{\dagger}$ With 2-methyltetrahydrofuran as the solvent.

Previous studies on the proline-mediated self-aldol reaction of propanal ${ }^{11 b, 16}$ or butanal $^{\text {th }}$ in water indicated that the reaction hardly proceeds in the presence of 10 mol\% of proline. In contrast, polymer 7 proved useful in the formation of the $\beta$-hydroxy aldehyde adducts with high stereoselectivity in an aqueous environment. Furthermore, dehydration products were not observed, probably as a consequence of the aqueous reaction conditions: in the presence of water, dehydration is much less favourable than when dry organic solvents are used. The role of water looks even more crucial if we consider that employing 2methyltetrahydrofuran as the solvent the stereoselectivities decrease significantly (Table 3, entry 4).

As a demonstration of the synthetic potential of immobilized proline 7, the self-aldol reaction of butanal was scaled up using 50 $\mathrm{mmol}$ of the aldehyde (Scheme 3). Lowering the catalyst loading to only 0.2 mol\% of resin 7 and under essentially neat conditions (just $0.3 \mathrm{~mL}$ of water were used), the reaction proceeded in 4 days to furnish the desired product 15 in $49 \%$ yield (1.17 $\mathrm{g}$ isolated product).

The operational simplicity associated to the catalytic use of resin $\mathbf{7}$ (simply adding a sample of wet resin $\mathbf{7}$ to the flask containing the aldehyde) is truly remarkable, with a behaviour reminiscent to the alchemysts' philosophers stone or to the brewers' ferments.

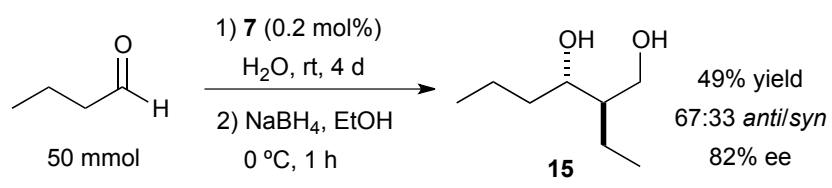

Scheme 3 Asymmetric self-aldol reaction of neat butanal using wet 7.

To further confirm the recyclability of $\mathbf{7}$, the dimerization of butanal was performed during ten consecutive runs with the same sample of this catalytic resin. After each run, it was recovered by simple filtration, rinsed with EtOAc, dried and directly reused in the next cycle (see Supporting Information for more details). Under these conditions, only a moderate decrease of catalytic activity was recorded at the end of the recycling test (Table 4).

Table 4 Recycling experiments of catalyst $\mathbf{7}$ in the self-aldol reaction of butanal ${ }^{\mathrm{a}}$

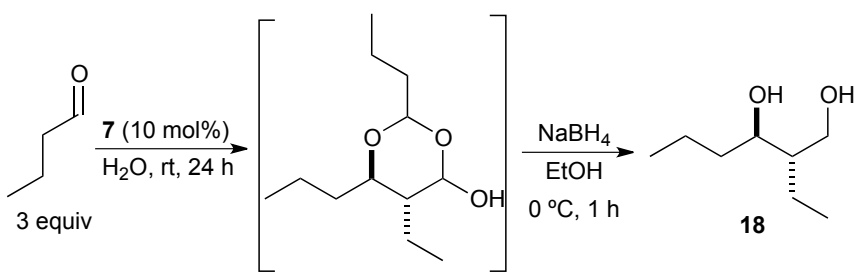




\begin{tabular}{cccc}
\hline Cycle & Yield [\%] $^{\mathrm{b}}$ & anti $/$ syn $^{\mathrm{c}}$ & ee anti $[\%]^{\mathrm{d}}$ \\
\hline 1 & 75 & $60: 40$ & 87 \\
2 & 85 & $68: 32$ & 92 \\
3 & 96 & $70: 30$ & 91 \\
4 & 94 & $70: 30$ & 90 \\
5 & 95 & $63: 37$ & 88 \\
6 & 94 & $68: 32$ & 86 \\
7 & 87 & $73: 27$ & 85 \\
8 & 75 & $75: 25$ & 84 \\
9 & 85 & $73: 26$ & 84 \\
10 & 83 & $70: 30$ & 83 \\
\hline
\end{tabular}

${ }^{a}$ Reactions were performed in water $(0.4 \mathrm{~mL})$ with butanal $(1 \mathrm{mmol})$ and resin $7(0.1 \mathrm{mmol}) .{ }^{\mathrm{b}}$ Isolated yield. ${ }^{\mathrm{c}}$ Determined by ${ }^{1} \mathrm{H} \mathrm{NMR}$ on a crude sample of the $1,3-\mathrm{diol}$. ${ }^{\mathrm{d}}$ Determined by chiral HPLC after conversion to the monobenzoate.

\section{Conclusions}

We have developed a polystyrene-supported organocatalyst based on proline (7) using a simple copolymerization strategy. The catalyst thus obtained is suitable for work under wet conditions, is notably robust and can be repeatedly reused with minimal loss of activity. Resin 7, which displays a completely regiodefined structure unlike analogous polymers based on commercial Merrifield resins, represents an innovative and sustainable catalyst design that shows excellent performance in both the selfaldolization and the cross-aldol reaction of aldehydes by simply using a small volume of water as solvent. From the operational point of view, the asymmetric direct coupling of aldehyde substrates mediated by $\mathbf{7}$ thus represents a green alternative for the rapid production of a range of enantiomerically and diastereomerically enriched 1,3-diols. In particular, the possibility of using the wet resin $\mathbf{7}$ as a catalyst (ferment) to induce the asymmetric self-aldol reaction of aliphatic aldehydes under essentially neat conditions represents, in our opinion, an important step towards the development of truly practical catalytic asymmetric processes fulfilling all the requirements of sustainable chemistry.

\section{Acknowledgments}

This work was funded by the Institute of Chemical Research of Catalonia (ICIQ) Foundation, MINECO (grant CTQ2015-69136-R) and DEC Generalitat de Catalunya (Grant 2014SGR827). We also thank MINECO for a Severo Ochoa Excellence Accreditation 2014-2018 (SEV-2013-0319).

\section{Notes and references}

1 (a) Modern Aldol Reactions, ed. R. Mahrwald, Wiley-VCH: Weinheim, 2004, vols. 1 and 2; (b) B. M. Trost, C. S. Brindle, Chem. Soc. Rev., 2010, 39, 1600; (c) V. Bisai, A. Bisai, V. K. Singh, Tetrahedron, 2012, 68, 4541; (d) G. Guillena, Modern Methods in Stereoselective Aldol Reactions, ed. R. Mahrwald, Wiley-VCH, 2013, pp. 155-268; (e) J. Mlynarski, S. Bas, Chem Soc. Rev., 2014, 43, 577.

2 A. B. Northrup, D. W. C. MacMillan, J. Am. Chem. Soc., 2002, 124, 6798.

3 For some representative examples of organocatalytic asymmetric cross-coupling of aldehydes, see: (a) I. K. Mangion, A. B. Northrup, D. W. C. MacMillan, Angew. Chem. Int. Ed., 2004, 43, 6722; (b) A. B. Northrup, I. K. Mangion, F. Hettche, D. W. C. MacMillan, Angew. Chem. Int. Ed., 2004, 43, 2152; (c) Y. Hayashi, T. Itoh, S. Aratake, H. Ishikawa, Angew. Chem. Int. Ed., 2008, 47, 2082; (d) M. Markert, U. Scheffletr, R. Mahrwald, J. Am. Chem. Soc., 2009, 131, 16642; (e) Y. Hayashi, Y. Yasui, T. Kawamura, M. Kojima, H. Ishikawa, Angew. Chem. Int. Ed., 2011, 50, 2804; (f) T. Kano, H. Sugimoto, K. Maruoka, J. Am. Chem. Soc., 2011, 133, 18130; (g) Q. Gao, Y. Liu, S.-M- Lu, J. Li, C. Li, Green Chem., 2011, 13, 1983; (h) X. Fan, C. Rodríguez-Escrich, S. Wang, S. Sayalero, M. A. Pericàs, Chem. Eur. J., 2014, 20, 13089.

4 For seminal works, see: (a) B. List, R. A. Lerner, C. F. Barbas III, J. Am. Chem. Soc., 2000, 122, 2395; (b) W. Notz, B. List, J. Am. Chem. Soc., 2000, 122, 7386; (c) K. Sakthivel, W. Notz, T. Bui, C. F. Barbas III, J. Am. Chem. Soc., 2001, 123, 5260; (d) B. List, Tetrahedron, 2002, 58, 5573; (e) A. Córdova, W. Notz, C. F. Barbas III, Chem. Commun., 2002, 3024.

5 (a) A. I. Nyberg, A. Usano, P. M. Pihko, Synlett, 2004, 11, 1891; (b) P. M. Pihko, K. M. Laurikainen, A. Usano, A. I. Nyberg, J. A. Kaavi, Tetrahedron, 2006, 62, 317; For the effect of water in proline-catalyzed aldol reactions: (c) A. P. Brogan, T. J. Dickerson, K. D. Janda, Angew. Chem. Int. Ed., 2006, 45, 8100; (d) N. Zotova, A. Franzke, A. Armstrong, D. G. Blackmond, J. Am. Chem. Soc., 2007, 129, 15100; (e) A. K. Sharma, R. B. Sunoj, Angew. Chem. Int. Ed., 2010, 49, 6373; (f) J. Ribas-Arino, M. A. Carvajal, A. Chaumont, M. Masia, Chem. Eur. J., 2012, 18, 15868.

6 For reviews, see: (a) M. Gruttadauria, F. Giacalone, R. Noto, Adv. Synth. Catal., 2009, 351, 33; (b) J. Paradowska, M. Stodulski, J. Mlynarski, Angew. Chem. Int. Ed., 2009, 48, 4288; (c) J. G. Hernandez, E. Juaristi, Chem. Commun., 2012, 48, 5396; (d) see also ref. $1 \mathrm{e}$.

7 For some selected examples see: (a) Y. Hayashi, T. Sumiya, J. Takahashi, H. Gotoh, T. Urushima, M. Shoji, Angew. Chem. Int. Ed., 2006, 45, 958; (b) Y. Hayashi, S. Aratake, T. Okano, J. Takahashi, T. Sumiya, M. Shoji, Angew. Chem. Int. Ed., 2006, 45, 5527; (c) Y. Hayashi, S. Aratake, T. Itoh, T. Okano, T. Sumiya, M. Shoji, Chem. Commun., 2007, 957; (d) Y. Chi, S. T. Scroggins, E. Boz, J. M. J. Fréchet, J. Am. Chem. Soc., 2008, 130, 17287; (e) B. H. Lipshutz, S. Ghorai, Org. Lett., 2012, 14, 422. 
8 (a) Chiral Catalysts Immobilization and Recycling, ed. D. E. De Vos, I. F. J. Vankelecom, P. A. Jacobs, Wiley-VCH: Weinheim, 2000; (b) T. Frezel, W. Solodenko, A. Kirsching, Solid-Phase Bound Catalysts: Properties and Applications, in Polymeric Materials in Organic Synthesis and Catalysis, ed. M. R. Buchmeiser, Wiley-VCH: Weinheim, 2003; (c) Recoverable and Recyclable Catalysts, ed. M. Benaglia, John Wiley \& Sons, Chichester, 2009; (d) K. E. Kristensen, T. Hansen, Eur. J. Org. Chem., 2010, 3179.

9 (a) F. Calderón, R. Fernández, F. Sánchez, A. Fernández-Mayoralas, Adv. Synth. Catal., 2005, 347, 1395; (b) O. Bortolini, L. Caciolli, A. Cavazzini, V. Costa, R. Greco, A. Massi, L. Pasti, Green Chem., 2012, 14, 992; (c) Z. An, Y. Guo, L. Zhao, Z. Li, J. He, ACS Catal., 2014, 4, 2566.

10 (a) Z. Yacob, A. Nan, J. Liebscher, Adv. Synth. Catal., 2012, 354, 3259; (b) Y. Kong, R. Tan, L. Zhao, D. Yin, Green Chem., 2013, 15, 2422; (c) H. A. Zayas, A. Lu, D. Valade, F. Amir, Z. Jia, R. K. O’Reilly, M. J. Monteiro, ACS Macro Lett., 2013, 2, 327; (d) A. Lu, D. Moatsou, I. Hands-Portman, D. A. Longbottom, R. K. O'Reilly, ACS Macro Lett., 2014, 3, 1235; (e) J. Bonnefoy, A. Legrand, E. A. Quadrelli, J. Canivet, D. Farrusseng, J. Am. Chem. Soc., 2015, 137, 9409; (f) M. C. M. van Oers, W. S. Veldmate, J. C. M. van Hest, F. P. J. T. Rutjes, Polymer Chem., 2015, 6, 5358.

11 For Merrifield-type resins, see: (a) D. Font, C. Jimeno, M. A. Pericàs, Org. Lett., 2006, 8, 4653; (b) D. Font, S. Sayalero, A. Bastero, C. Jimeno, M. A. Pericàs, Org. Lett., 2008, 10, 337; (c) C. Ayats, A. H. Henseler, M. A. Pericàs, ChemSusChem, 2012, 5, 320; For polynorbornene supports, see: (d) I. K. Sagamanova, S. Sayalero, S. Martínez-Arranz, A. C. Albéniz, M. A. Pericàs, Catal. Sci. Technol., 2015, 5, 754.

12 For PEG-supported proline, see: (a) M. Benaglia, G. Celentano, F. Cozzi, Adv. Synth. Catal., 2001, 343, 171; (b) M. Benaglia, M. Cinquini, F. Cozzi, A. Puglisi, G. Celentano, Adv. Synth. Catal., 2002, 344, 533; For proline supported on polystyrene: (c) F. Giacalone, M. Gruttadauria, A. M. Marculescu, R. Noto, Tetrahedron Lett., 2007, 48, 255; (d) M. Gruttadauria, F. Giacalone, A. M. Marculescu, P. Lo Meo, S. Riela, R. Noto, Eur. J. Org. Chem., 2007, 4688; For proline functionalized styrenic and methacrylic copolymers, see: (e) T. E. Kristensen, K. Vestli, K. A. Fredriksen, F. K. Hansen, T. Hansen, Org. Lett., 2009, 11, 2968; (f) T. E. Kristensen, K. Vestli, M. G. Jakobsen, F. K. Hansen, T. Hansen, J. Org. Chem., 2010, 75, 1620; For proline functionalized polystyrene copolymers, see: (g) A. C. Evans, A. Lu, C. Ondeck, D. A. Longbottom, R. K. O'Reilly, Macromolecules, 2010, 43, 6374; (h) A. Lu, T. P. Smart, T. H. Epps, III, D. A. Longbottom, R. K. O'Reilly, Macromolecules, 2011, 44, 7233.

13 (a) R. Huisgen, Proc. Chem. Soc., 1961, 357; (b) R. Huisgen, 1,3-Dipolar Cycloaddition Chemistry, ed. A. Padwa, Wiley, New York, 1984; (c) M. Meldal, C. W. Tornøe, Chem. Rev., 2008, 108, 2952.

14 (a) D. C. Sherrington, Chem. Commun., 1998, 2275; (b) P. Besenius, P. A. G. Cormack, J. Liu, S. Otto, J. K. M. Sanders, D. C. Sherrington, Chem. Eur. J., 2008, 14, 9006.

15 In the formula representing the immobilized catalyst 7, the coloured circle refers to the polymer backbone. We have chosen to explicitly represent the $p$-oxymethylbenzyl unit to indicate the well defined substitution pattern in this fragment.

16 S. Aratake, I. Takahiko, O. Tsubasa, U. Takahiro, S. Mitsuru, Y. Hayashi, Chem. Commun., 2007, 2524. 